\title{
Effects of Particle Size and Surface Chemistry on the Dispersion of Graphite Nanoplates in Polypropylene Composites
}

\author{
Raquel M. Santos ${ }^{1}$, Sacha T. Mould ${ }^{1}$, Petr Formánek ${ }^{2}$, Maria C. Paiva ${ }^{1, * \mathbb{C}}$ and José A. Covas ${ }^{1, *}$ \\ 1 Institute for Polymers and Composites/I3N, University of Minho, Campus de Azurém, \\ 4800-058 Guimarães, Portugal; rmsantos@inegi.up.pt (R.M.S.); sacha.tm@dep.uminho.pt (S.T.M.) \\ 2 Leibniz Institute for Polymer Research Dresden, Hohe Strasse 6, D-01069 Dresden, Germany; \\ formanek@ipfdd.de \\ * Correspondence: mcpaiva@dep.uminho.pt (M.C.P.); jcovas@dep.uminho.pt (J.A.C.); \\ Tel.: +351-253-510-320 (M.C.P. \& J.A.C.)
}

Received: 8 December 2017; Accepted: 21 February 2018; Published: 24 February 2018

\begin{abstract}
Carbon nanoparticles tend to form agglomerates with considerable cohesive strength, depending on particle morphology and chemistry, thus presenting different dispersion challenges. The present work studies the dispersion of three types of graphite nanoplates $(\mathrm{GnP})$ with different flake sizes and bulk densities in a polypropylene melt, using a prototype extensional mixer under comparable hydrodynamic stresses. The nanoparticles were also chemically functionalized by covalent bonding polymer molecules to their surface, and the dispersion of the functionalized $\mathrm{GnP}$ was studied. The effects of stress relaxation on dispersion were also analyzed. Samples were removed along the mixer length, and characterized by microscopy and dielectric spectroscopy. A lower dispersion rate was observed for $\mathrm{GnP}$ with larger surface area and higher bulk density. Significant re-agglomeration was observed for all materials when the deformation rate was reduced. The polypropylene-functionalized $\mathrm{GnP}$, characterized by increased compatibility with the polymer matrix, showed similar dispersion effects, albeit presenting slightly higher dispersion levels. All the composites exhibit dielectric behavior, however, the alternate current (AC) conductivity is systematically higher for the composites with larger flake GnP.
\end{abstract}

Keywords: graphite nanoplates; surface modification; polymer composites; dispersion

\section{Introduction}

Polymer matrix-based nanocomposites have attracted intensive research and development effort, due to their potential for developing novel, cost-effective, and high-performance products for advanced engineering applications, for example, in aerospace, automotive, construction, and medicine. The development of nanocomposites with high thermal and electrical conductivity, which are normally based on the incorporation of conductive carbon nanostructures (graphite and its derivatives, graphene, carbon nanotubes, and fullerenes) [1,2], motivates particular attention given their promising applications in single molecule gas detection, transparent conducting electrodes, energy storage (supercapacitors and lithium ion batteries), transportation devices, refractory and fire-proof materials, etc. [3-5].

Graphite is the most thermodynamically stable and softest (1 in the Mohs hardness scale) form of carbon with high stiffness (1 TPa), and good electrical $\left(>10^{3} \mathrm{~S} \cdot \mathrm{m}^{-1}\right)$ and in-plane thermal $\left(\sim 2000 \mathrm{~W} \cdot \mathrm{m}^{-1} \cdot \mathrm{K}^{-1}\right)$ conductivities [4,5]. Intercalation of graphite by electron donors (alkali metals) or electron acceptors (acids, halogens, and halide ions) allows for increasing the interlayer spacing and weakening the van der Waals interactions, yielding expanded graphite, with particle sizes around $300-500 \mu \mathrm{m}[6,7]$. This is a material of high interest for fire protection [8]. When submitted to a critical 
temperature or microwave radiation, intercalated graphite can expand hundreds of times relative to its initial volume, due to vaporization of the intercalate, forming exfoliated graphite (EG) [9]. In turn, ultrasonication of the latter in specific solvents or surfactant solutions results in stable suspensions (with particle sizes typically lower than $50 \mu \mathrm{m}$ ), usually designated as graphite nanoplates $(\mathrm{GnP})$ [10].

In order to reach its optimal effect as composite reinforcement, graphite should be exfoliated as much as possible into its separate layers. In practice, the effective dispersion of $\mathrm{GnP}$ in polymeric matrices remains difficult, not only due to their inherent tendency to form cohesive clusters [11], but also because the chemical inertia of $\mathrm{GnP}$ precludes the development of strong interfaces with polymers. Surface modification of the nanoparticles may minimize these limitations. It can be achieved via non-covalent or covalent approaches [12]. Covalent functionalization allows the formation of strong and stable interfaces with polymeric matrices by chemical bonding of functional groups to the aromatic carbon lattice of graphene. The prevalent strategy consists on the chemical oxidation of the graphene surfaces as described by Brodie [13], Staudenmaier [14], and Hummers [15]. However, these procedures disturb the conjugated nature of the graphitic lattice by local bonding of oxygen-containing groups, shifting its hybridization state from $s p^{2}$ to $s p^{3}$, as indicated by Raman spectroscopy studies [16,17]. Reactions involving the cycloaddition to the $\pi$-electrons of the graphene lattice were successfully applied to carbon nanotubes [18,19], carbon nanofillers [20], and graphite nanoplates [3] under mild conditions, leading to little or no damage of their structural integrity.

Currently, it is well accepted that the dispersion of carbon nanoparticles into polymeric matrices and the electrical percolation threshold of nanocomposites are strongly dependent on nanoparticle surface chemistry [3,21,22], agglomerate density and strength [23,24], size [25], aspect ratio [26], purity [27], alignment [28,29], as well as on polymer type [30] and viscosity [31-33]. The influence of the majority of these parameters has been well documented for multi-walled carbon nanotubes/polymer composites, while studies with GnP/polymer composites are less abundant $[3,11,25,29,34-36]$. In particular, a thorough understanding of the dispersion and re-agglomeration phenomena of $\mathrm{GnP}$ in polymer melts is still lacking. Vilaverde et al. [11] investigated the dispersion and re-agglomeration of 2 and $10 \mathrm{wt} \%$ of GnP in polypropylene (PP) during flow under well-controlled conditions. A gradual decrease of the number and size of the $\mathrm{GnP}$ agglomerates was observed, regardless of the shear rate, but the magnitude of the changes was highly dependent on graphite concentration. At sufficiently low shear rates, interparticle interactions induced GnP re-agglomeration. Santos et al. [3] demonstrated that chemical modification of GnP via 1,3 dipolar cycloaddition enhanced the stability of dispersion and delayed re-agglomeration.

In this work, the effects of morphology and surface chemistry of GnP on dispersion and re-agglomeration in polypropylene are investigated. Composites containing $2 \mathrm{wt} \% \mathrm{of} \mathrm{GnP}$ with different morphology, as-received or functionalized, were prepared using a prototype small-scale extensional mixer coupled to a capillary rheometer, in order to generate well controlled flows in terms of volumetric rate and temperature. Samples of the composites were collected along the length of the mixer and cooled in liquid nitrogen for subsequent analysis. Dispersion and re-agglomeration were analyzed by microscopy, and the electrical conductivity of the composites was measured.

\section{Experimental}

\subsection{Materials}

Polypropylene copolymer (Icorene CO14RM ${ }^{\circledR}$, from ICO Polymers, Inc., Allentown, PA, USA), in powder form, with a melt flow index of $13 \mathrm{~g} \cdot 10 \mathrm{~min}^{-1}\left(190{ }^{\circ} \mathrm{C}, 2.16 \mathrm{Kg}\right)$ and a density of 0.9 , was used as matrix. Three commercially available graphite nanoplates were obtained from XG Sciences (Lansing, MI, USA), their properties being summarized in Table 1 according to the company data sheets.

GnP were chemically functionalized via 1,3-dipolar cycloaddition (DCA) of an azomethine ylide, as reported elsewhere [18]. The reaction was carried out using $\mathrm{N}$-benzyloxycarbonylglycine (Z-GLY-OH) 99\% from Sigma Aldrich (St. Louis, MO, USA) and paraformaldehyde reagent grade, 
from Sigma Aldrich (St. Louis, MO, USA), homogeneously mixing with the GnP in powder form, and maintained at $250{ }^{\circ} \mathrm{C}$ for $3 \mathrm{~h}$. The pyrrolidine groups formed at the surface of functionalized $\mathrm{GnP}$ were further covalently bonded to polypropylene-graft-maleic anhydride (PP-g-MA) containing 8-10 wt \% of maleic anhydride, supplied by Sigma-Aldrich (St. Louis, MO, USA), to produce GnP covalently functionalized with PP-g-MA ( $f \mathrm{GnP}-\mathrm{PP})$. The reaction was performed by refluxing in toluene during $3 \mathrm{~h}$. Extensive washing with hot toluene was carried out to remove the excess PP-g-MA, and the remaining material was dried in an oven overnight at $100{ }^{\circ} \mathrm{C}$.

Table 1. Properties of the as-received graphite nanoplates.

\begin{tabular}{|c|c|c|c|c|c|c|c|}
\hline$x G n P$ & $\begin{array}{c}\text { Carbon } \\
\text { purity }(\%)\end{array}$ & $\begin{array}{l}\text { Bulk } \\
\text { density }\end{array}$ & Density & $\begin{array}{l}\text { Width } \\
(\mu \mathrm{m})\end{array}$ & $\begin{array}{c}\text { Thickness } \\
\text { (nm) }\end{array}$ & $\begin{array}{l}\text { Surface area } \\
\left(\mathrm{m}^{2} \cdot \mathrm{g}^{-1}\right)\end{array}$ & $\begin{array}{l}\text { Electrical conductivity } \\
\text { in plane/perpendicular } \\
\text { to surface }\left(\mathrm{S} \cdot \mathrm{m}^{-1}\right)\end{array}$ \\
\hline xGnP Grade $C^{\circledR}$ & 98.0 & $0.20-0.40$ & $2.0-2.25$ & $1-2$ & 2 & 750 & Not available \\
\hline xGnP Grade $\mathrm{M}^{\circledR}$ & $>99.5$ & $0.03-0.10$ & 2.2 & 15 & 6-8 & $120-150$ & $10^{7} / 10^{2}$ \\
\hline$x$ GnP Grade $H^{\circledR}$ & $>99.5$ & $0.03-0.10$ & 2.2 & 5 & 15 & $60-80$ & $10^{7} / 10^{2}$ \\
\hline
\end{tabular}

\subsection{Processing of Nanocomposites}

PP nanocomposites containing $2 \mathrm{wt} \%$ of as-received GnP or $f \mathrm{GnP}-\mathrm{PP}$, pre-mixed in powder form, were processed in a small-scale extensional mixer attached to a Rosand RH10 capillary rheometer (Malvern Instruments Limited, Malvern, UK), heated to a predefined temperature, and forced through the system at $50 \mathrm{~mm} \cdot \mathrm{min}^{-1}$, after preheating for $5 \mathrm{~min}$. This $\mathrm{GnP}$ loading and flow rate were selected based on previous dispersion studies of 2 and $10 \mathrm{wt} \% \mathrm{GnP}$ in PP [3,11], demonstrating that monitoring dispersion and re-agglomeration of nanocomposites containing high $\mathrm{GnP}$ concentrations was hindered by the large amount of agglomerates present. The temperature was adjusted so that the total pressure drop, i.e., the hydrodynamic stresses, would remain approximately uniform.

The mixer consists of three main sections (see Figure 1). Initially, the material streams through a sequence of 10 circular channels with alternating diameters, $d(d=1$ and $d=8 \mathrm{~mm}$, length $=2 \mathrm{~mm}$ ) that create a series of converging/diverging flows, with a strong extensional component (this will be denoted as first mixing zone). The average shear rate attains approximately $1500 \mathrm{~s}^{-1}$ in the smaller channels. As demonstrated by Grace [37] for liquid suspensions, normal stresses are more efficient for dispersion than shear stresses. Consequently, at the outlet of this first mixing zone, extensive dispersion levels are anticipated. In order to assess the stability of the dispersion achieved, the material enters the second section of the mixer, which contains a larger cylindrical channel $(d=18 \mathrm{~mm}$ and length $=24 \mathrm{~mm})$ where shear rates are negligible $\left(0.3 \mathrm{~s}^{-1}\right.$ in the experiments performed). Stress relaxation occurs, and re-agglomeration could eventually develop. The third section of the mixer is identical to the first one (and denoted as second mixing zone). The aim here is to subject the composite to similarly high deformation rates, and again, induce dispersion. The set-up is of modular construction. It is not only possible to vary the number and geometry of the individual channels, but material samples can be collected from the larger channels (with $d=8$ and $d=18 \mathrm{~mm}$ ), as well as from the reservoir of the rheometer, cooled in liquid nitrogen, and subsequently characterized. It was shown that the levels of dispersion obtained with this device are comparable to those achieved with the frequently used twin screw extruder $[22,38]$. 


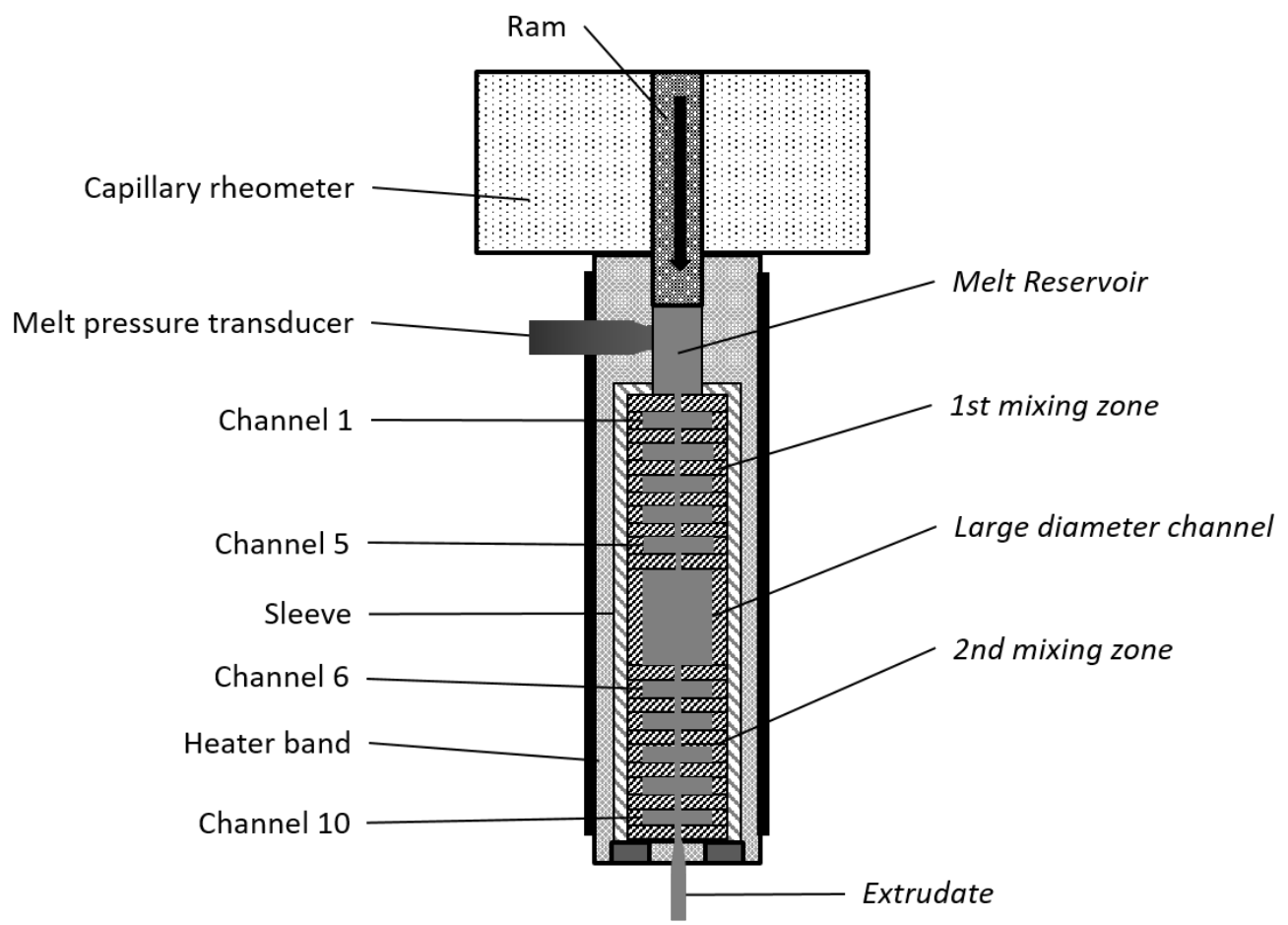

Figure 1. Prototype small-scale mixer, with two mixing zones separated by a large diameter channel. Each mixing zone contains a series of circular channels with alternating diameters, creating sequences of converging/diverging flows. Removing the sleeve and separating the individual rings gives access to material samples for subsequent characterization.

\subsection{Characterization of Graphite Nanoplates}

The area of the as-received GnP and $f \mathrm{GnP}$-PP primary particle agglomerates was measured by optical microscopy (OM) using a BH2 Olympus microscope attached to a Leica DFC 280 digital camera (Hamburg, Germany). Samples were prepared by hand mixing a small amount of GnP in epoxy resin, spreading a thin layer on a glass slide, and curing it at room temperature overnight. At least 130 optical micrographs were analyzed for each powder type. The morphology of the as-received $\mathrm{GnP}$ and $f \mathrm{GnP}-\mathrm{PP}$ was characterized by transmission electron microscopy (TEM), by means of a JEOL (Peabody, MA, USA) JEM1010 equipped with a CCD Orius camera and a tungsten filament as electron source, at an acceleration voltage of $100 \mathrm{kV}$ (GnPC and GnPH), and a Philips CM20 with EDS system at an acceleration voltage of $200 \mathrm{kV}(\mathrm{GnPH})$. Particles were previously dispersed in a dilute butyl alcohol solution $\left(1.2 \mathrm{~g} \cdot \mathrm{L}^{-1}\right)$, submitted to ultrasonication for two hours, deposited on a carbon coated copper grid, and dried under a lamp.

\subsection{Characterization of Nanocomposites}

$\mathrm{PP} / \mathrm{GnP}$ nanocomposite sections with a thickness of $10 \mu \mathrm{m}$ were cut perpendicularly and parallel to the flow direction with a Leitz 1401 microtome at room temperature, using glass knives with an angle of $45^{\circ}$. Optical micrographs were acquired using a Leica DFC 280 digital camera coupled to a BH2 Olympus microscope. For each composite, at least 12 micrographs were analyzed using Image ${ }^{\circledR}$ software (open source), leading to an investigated total area of $4.2 \mathrm{~mm}^{2}$. The area of the agglomerates larger than $5 \mu \mathrm{m}^{2}$ was measured, implying that smaller agglomerate areas were not accounted for in the statistical study. The total number of agglomerates measured for the analysis $(N)$ was identified. The average agglomerate area $\left(A_{\mathrm{av}}\right)$ was calculated, as well as its variance within a confidence interval of $95 \%$. The parameters used to describe the degree of $\mathrm{GnP}$ dispersion were the agglomerate area ratio $\left(A_{\mathrm{r}}\right)$ and the number of agglomerates per unit area $\left(N_{\mathrm{A}}\right) . A_{\mathrm{r}}$ is defined as the ratio between the sum 
of the areas of all agglomerates $\left(\sum \mathrm{GnP}\right)$ and the total composite area analyzed $\left(A_{\mathrm{T}}\right)$, as indicated in Equation (1),

$$
A_{r}=\frac{\sum \mathrm{GnP}}{A_{\mathrm{T}}} \times 100
$$

thus providing a convenient overall dispersion index. A cumulative distribution of the agglomerate areas can be defined as

$$
C A_{\mathrm{j}}=\frac{\sum_{i=1}^{j} A_{\mathrm{i}}}{\sum \mathrm{GnP}} \times 100
$$

where $\sum A_{\mathrm{i}}$ is the summation of the areas of the individual agglomerates $i$ in ascending area order. $C A_{j}$ provides detailed information about the size distribution of the surviving agglomerates. For example, it allows for the comparison of the agglomerate area populations of the composites collected along the mixer.

TEM analysis of the GnPC composite was carried out in a Libra 120 microscope (Carl Zeiss Microscopy GmbH, Oberkochen, Germany) at $120 \mathrm{kV}$. The specimens were cut into approx. $80 \mathrm{~nm}$ thin sections with a diamond knife (DiATOME AG, Biel, Switzerland) using an Ultracut UC6 ultramicrotome (Leica Microsystems $\mathrm{GmbH}$, Wetzlar, Germany).

The alternate current (AC) electrical conductivity of PP/GnP nanocomposites was measured with a Quadtech (Sussex, WI, USA) 1920 Precision LCR meter directly on the disks collected from the last flow channel, near to the mixer outlet. Experiments were performed at room temperature at a voltage of $1 \mathrm{~V}$, in the frequency range of $5 \times 10^{2}-1 \times 10^{6} \mathrm{~Hz}$. Circular contacts with a diameter of $6 \mathrm{~mm}$ and a thickness of $50 \mathrm{~nm}$ were produced by magnetron sputtering of gold/palladium.

\section{Results and Discussion}

\subsection{Graphite Nanoplates Size and Morphology}

Graphite nanoplates with different widths and thicknesses (see Table 1) were supplied in powder form. Typically, their primary nanoparticles form agglomerates with high cohesive strength, which has practical consequences on the rate and intensity of dispersion in the polymer melt during nanocomposite processing. The average area of the as-received $\mathrm{GnP}$ and $f \mathrm{GnP}-\mathrm{PP}$ primary nanoparticle agglomerates, and the significance within a $95 \%$ confidence interval, was calculated and is presented in Table 2. Different average areas were measured for each GnP type, and it was consistently observed that the nanoparticles functionalized with PP-g-MA formed larger agglomerates. Figure 2 depicts TEM micrographs of all powders used in this work, showing their flake morphology. As-received GnPC is composed of smaller flakes compared to GnPM and $\mathrm{GnPH}$. After surface chemical modification, the morphology of all graphite nanoplates seems to be maintained, despite the increase in size, suggesting that the method carried out under the conditions described does not induce damage of the GnP structure.

Table 2. Average area of the GnP primary nanoparticle agglomerates and significance within a $95 \%$ confidence interval.

\begin{tabular}{cc}
\hline GnP powder & Average area of the GnP powders $\left(\boldsymbol{\mu m}^{\mathbf{2}}\right)$ \\
\hline GnPC & $45 \pm 4$ \\
$f \mathrm{GnPC}-\mathrm{PP}$ & $71 \pm 12$ \\
GnPM & $326 \pm 34$ \\
$f \mathrm{GnPM}-\mathrm{PP}$ & $758 \pm 123$ \\
GnPH & $194 \pm 11$ \\
$f \mathrm{GnPH}-\mathrm{PP}$ & $289 \pm 17$ \\
\hline
\end{tabular}



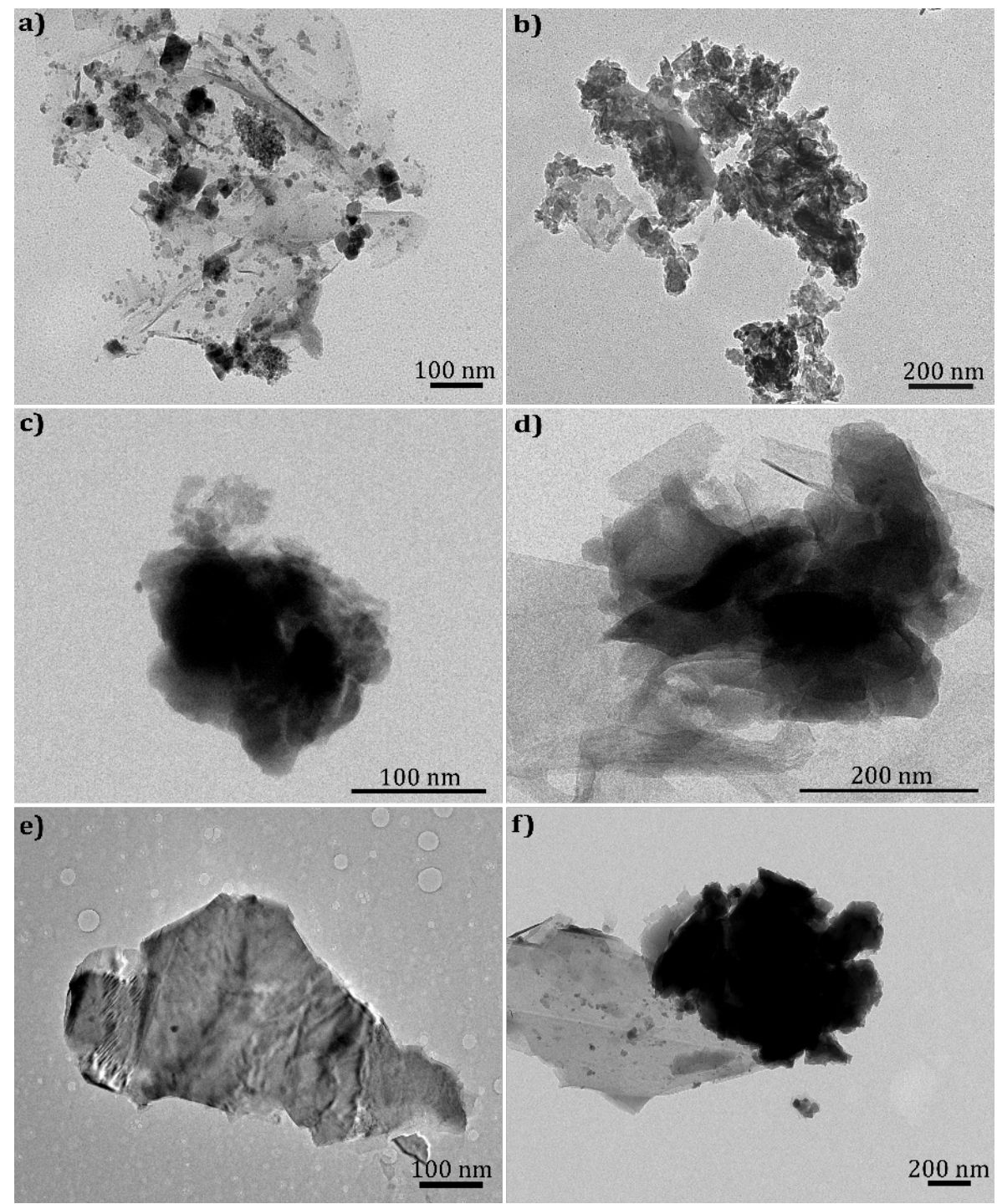

Figure 2. TEM micrographs of as-received GnPC, GnPM, and GnPH (a,c,e) and fGnPC-PP, fGnPM-PP, and $f \mathrm{GnPH}-\mathrm{PP}(\mathbf{b}, \mathbf{d}, \mathbf{f})$.

\subsection{Dispersion of the Graphite Nanoplates in Polypropylene}

Optical micrographs illustrating the morphology of the $\mathrm{GnP}$ agglomerates for as-received and functionalized $\mathrm{GnP}$ in the PP nanocomposites are presented in Figure 3. The images depict the changes in $\mathrm{GnP}$ agglomerate size as the melt progresses along the extensional mixer, from the reservoir of the capillary rheometer to the exit of the mixer. In channel 3, the composite has been subjected to three converging/diverging flows. Channel 5 corresponds to the fifth and last converging/diverging sequence of the first mixing zone, before the material advances in the larger cylindrical channel into channel 8. The melt was again subjected to three converging/diverging flows. Finally, channel 10 induces the last converging/diverging sequence prior to the material exiting the mixer (thus, channels 8 and 10 belong to the second mixing zone). Differences in size of the agglomerates at the various locations along the mixer are readily identifiable, with a notorious increase in size in the long channel. Differences in the behavior of the various grades of GnP are also evident. TEM micrographs of the GnPC composites presented in Figure 4 illustrate the dispersion effect as observed at high magnification. At the nanometer scale, larger and denser agglomerates are observed at the reservoir, becoming smaller after channel 3, reforming inside the large channel (although appearing to be less dense), and decreasing in size again after passing channel 10. 
The results of the OM analysis are summarized in Table 3, which presents, for the same locations of the mixer in Figure 3, and also at the reservoir of the rheometer, the average agglomerate areas $\left(A_{\mathrm{av}}\right)$ and their significance within a $95 \%$ confidence interval, the number of agglomerates per unit area of the composite sections analyzed $\left(N_{\mathrm{A}}\right)$, and the total number of agglomerates measured for the analysis $(N)$. Interestingly, the $A_{\mathrm{av}}$ of the as-received and functionalized $\mathrm{GnP}$ agglomerates in the composite collected from the reservoir are approximately three times smaller than the corresponding powder average area, for all GnP types (Table 2). This is indicative that pressing the powder and melting the polymer by heat conduction from the barrel of the rheometer and flow under low shear rate create enough thermomechanical stresses to initiate GnP agglomerate breakage. From the reservoir to channel 5, a decrease in $\mathrm{GnP}$ size, as well as in the number of agglomerates per unit area of composite cross-section, is evident for all $\mathrm{GnP}$ grades and functionalized equivalents. At the large cylindrical channel, where the average shear rate is very low $\left(\sim 0.3 \mathrm{~s}^{-1}\right)$ and the local residence time is substantial, the $\mathrm{GnP}$ agglomerates reorganize and undergo re-agglomeration. The area of the agglomerates rises to values close to those of the agglomerates present inside the reservoir of the rheometer. Simultaneously, the number of agglomerates per unit area, $N_{\mathrm{A}}$, increases relative to those present in channel 5 , although they are less than those in the reservoir, for all GnP types. This could suggest that the morphology/cohesiveness of the new agglomerates might be distinct from those in the melt in the reservoir. In the second mixing zone (from channel 6 to channel 10), the average size of the agglomerates reduces, demonstrating again that increasing the shear rate resets dispersion. The $A_{\mathrm{av}}$ reached in channel 10 is similar to that achieved in channel 5. These results are globally in line with those obtained for PP/MWCNT composites being processed and reprocessed under identical operating conditions $[38,39]$.

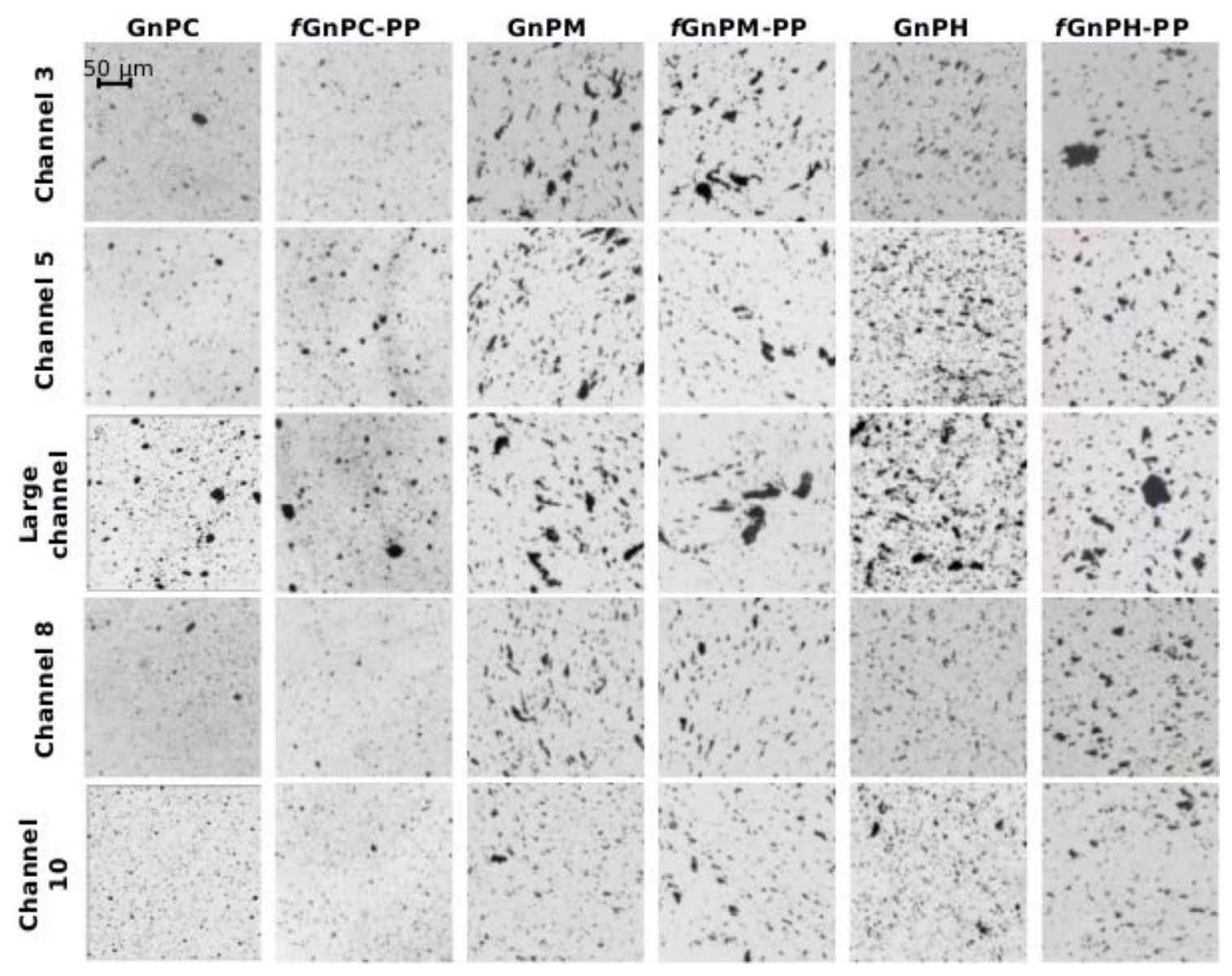

Figure 3. Optical micrographs of samples of PP nanocomposites containing GnP and $f$ GnP-PP collected from a prototype small-scale extensional mixer. 

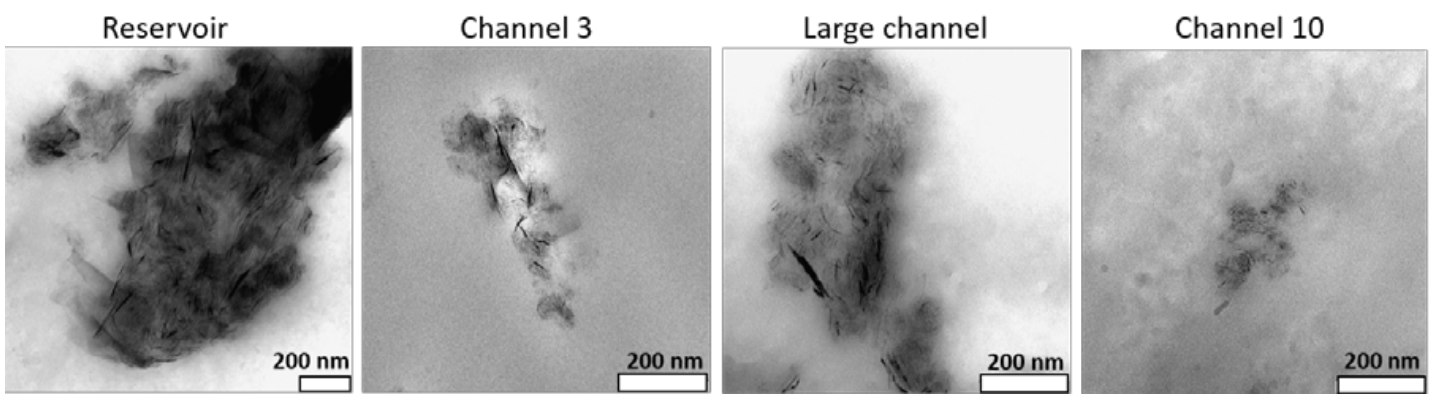

Figure 4. TEM micrographs of the GnPC composite collected along the extensional mixer.

Table 3. Characterization of dispersion and re-agglomeration of PP nanocomposites containing 2 wt \% of as-received $\mathrm{GnP}$ and $f \mathrm{GnP}-\mathrm{PP}$ during flow in a prototype small-scale extensional mixer.

\begin{tabular}{|c|c|c|c|c|c|c|}
\hline $\begin{array}{c}\text { Location in } \\
\text { extensional mixer }\end{array}$ & $A_{\mathrm{av}}\left(\mu \mathrm{m}^{2}\right)^{*}$ & $N_{\mathrm{A}}\left(\mathrm{mm}^{-2}\right)$ & $N$ & $A_{\mathrm{av}}\left(\mu \mathrm{m}^{2}\right) *$ & $N_{\mathrm{A}}\left(\mathrm{mm}^{-2}\right)$ & $N$ \\
\hline & \multicolumn{3}{|c|}{$\mathrm{PP} / \mathrm{GnPC}$} & \multicolumn{3}{|c|}{$\mathrm{PP} / f \mathrm{GnPC}-\mathrm{PP}$} \\
\hline Reservoir & $15.0 \pm 0.9$ & 240.7 & 4289 & $24 \pm 8$ & 2000.3 & 1828 \\
\hline Channel 3 & $14 \pm 2$ & 152.2 & 862 & $12 \pm 2$ & 275.4 & 1722 \\
\hline Channel 5 & $10.7 \pm 0.7$ & 74.93 & 1650 & $10 \pm 1$ & 131.5 & 1237 \\
\hline Large channel & $14.6 \pm 0.8$ & 167.4 & 3989 & $14 \pm 4$ & 634.0 & 1170 \\
\hline Channel 8 & $18 \pm 2$ & 139.5 & 1046 & $12 \pm 2$ & 279.1 & 1436 \\
\hline \multirow[t]{2}{*}{ Channel 10} & $14.6 \pm 0.9$ & 88.48 & 1298 & $10 \pm 1$ & 191.3 & 1335 \\
\hline & \multicolumn{3}{|c|}{$\mathrm{PP} / \mathrm{GnPM}$} & \multicolumn{3}{|c|}{ PP/fGnPM-PP } \\
\hline Reservoir & $131 \pm 19$ & 1895.1 & 827 & $120 \pm 19$ & 1510.4 & 744 \\
\hline Channel 3 & $63 \pm 6$ & 644.8 & 1243 & $72 \pm 8$ & 571.2 & 880 \\
\hline Channel 5 & $51 \pm 4$ & 367.4 & 1268 & $56 \pm 6$ & 530.1 & 920 \\
\hline Large channel & $83 \pm 4$ & 1712.2 & 1288 & $110 \pm 14$ & 1113.0 & 800 \\
\hline Channel 8 & $47 \pm 4$ & 543.4 & 1626 & $64 \pm 8$ & 745.2 & 951 \\
\hline \multirow[t]{2}{*}{ Channel 10} & $40 \pm 4$ & 575.1 & 1511 & $60 \pm 6$ & 498.0 & 805 \\
\hline & \multicolumn{3}{|c|}{$\mathrm{PP} / \mathrm{GnPH}$} & \multicolumn{3}{|c|}{ PP/fGnPH-PP } \\
\hline Reservoir & $65 \pm 7$ & 1157.6 & 1975 & $110 \pm 17$ & 1814.9 & 975 \\
\hline Channel 3 & $38 \pm 3$ & 297.4 & 2331 & $57 \pm 6$ & 476.4 & 901 \\
\hline Channel 5 & $32 \pm 2$ & 267.7 & 2197 & $50 \pm 5$ & 388.4 & 994 \\
\hline Large channel & $56 \pm 5$ & 606.0 & 2067 & $71 \pm 11$ & 1182.8 & 1031 \\
\hline Channel 8 & $38 \pm 3$ & 384.6 & 1953 & $62 \pm 8$ & 823.5 & 1034 \\
\hline Channel 10 & $34 \pm 3$ & 360.4 & 1582 & $55 \pm 7$ & 588.2 & 862 \\
\hline
\end{tabular}

* Average agglomerate area considering the $N$ agglomerates measured with a confidence interval of $95 \%$.

Figure 5 displays the cumulative distribution of the agglomerate areas, $C A_{\mathrm{i}}$, for the as-received and chemically modified particles. For the sake of clarity, only the cumulative distributions of the agglomerate areas of the composites in the reservoir, channel 5 (end of first mixing zone), large channel (where nanoparticle re-agglomeration was observed), and channel 10 (end of second mixing zone) are represented. The composites with all GnP types, with and without functionalization, present a wide distribution of agglomerate areas with large agglomerates in the reservoir, while the narrower distributions with smaller agglomerates are mostly observed in channel 5 . The large channel allows substantial re-agglomeration, reforming large agglomerates and presenting a wide distribution of agglomerate areas, although smaller than measured in the reservoir. Finally, in channel 10, at the exit of the second mixing zone, the agglomerates are smaller and form a narrow distribution, approaching that observed in channel 5. GnPC and fGnPC-PP form considerably smaller agglomerates compared to GnPM, fGnPM-PP, GnPH, and $f \mathrm{GnPH}-\mathrm{PP}$. The cumulative distributions of the agglomerates formed by GnPM and GnPH are of comparable width, with agglomerate sizes of similar magnitude. 
Functionalization of the nanoparticles did not significantly change the range of agglomerate sizes formed.
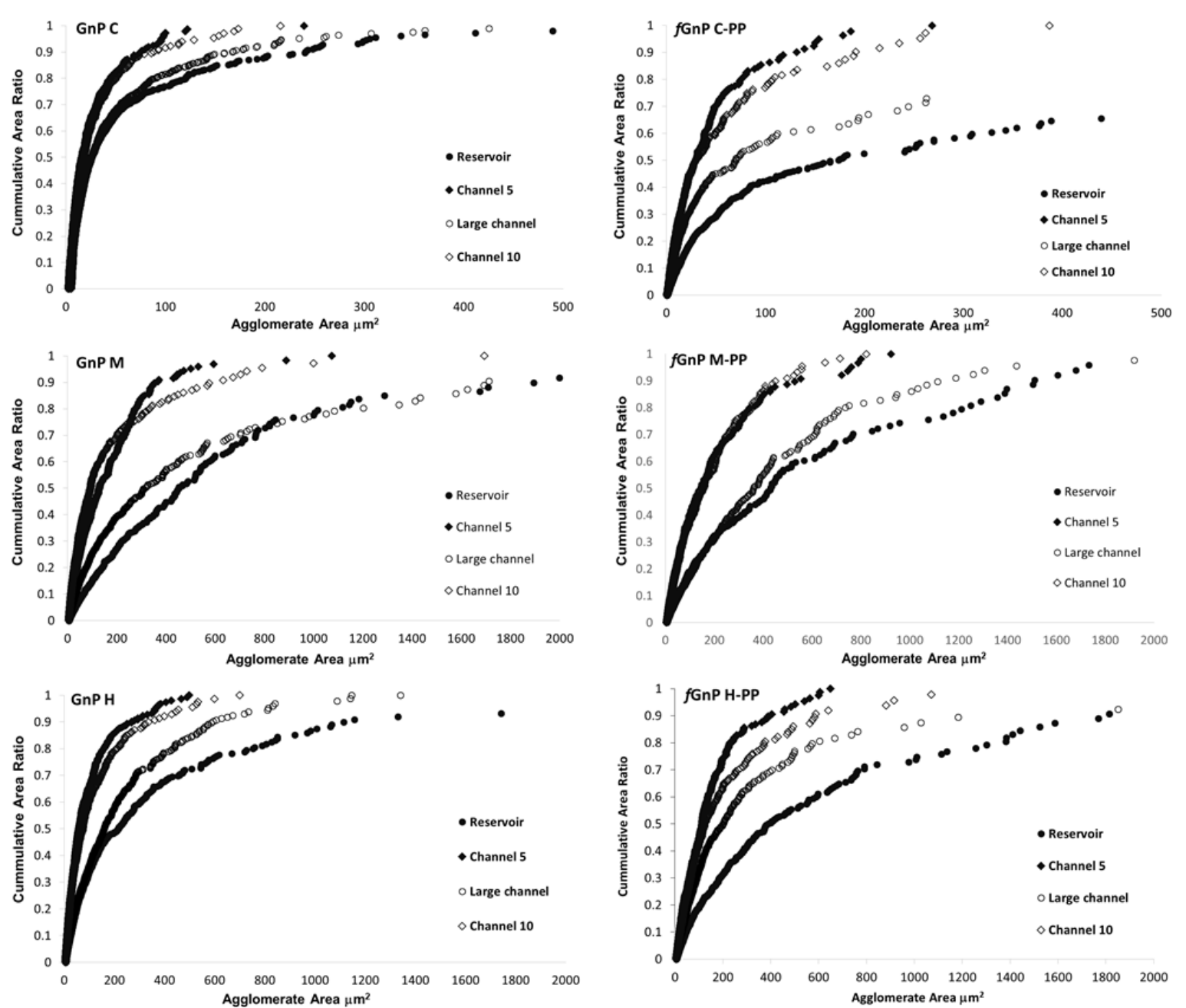

Figure 5. Representation of the cumulative agglomerate area distribution measured for the PP/GnP and PP/fGnP-PP composites collected along the mixer.

The state of dispersion of carbon nanoparticles is commonly associated to the inverse of $A_{\mathrm{r}}$, i.e., complete dispersion at the microscopic level corresponds to $A_{\mathrm{r}}=0$, while composites containing a large number of agglomerates and/or large agglomerate areas present high values of $A_{r}$. The $A_{\mathrm{r}}$ values obtained for $\mathrm{GnPC}, \mathrm{GnP} \mathrm{M}$, and $\mathrm{GnPH}$ and functionalized equivalents, are depicted in Figure 6. In all cases, $A_{\mathrm{r}}$ shows a consistent, almost linear, decrease from the reservoir to the end of the first mixing section (channel 5). Two samples from the large channel were collected and analyzed, one from a location near to its entrance, the other near to the exit. Figure 6 clearly demonstrates that a systematic increase of $A_{\mathrm{r}}$ along the relaxation chamber takes place, showing evidence for GnP or $f \mathrm{GnP}-\mathrm{PP}$ re-agglomeration. The values of $A_{\mathrm{r}}$ attained approach those measured upstream in the reservoir (channel 0). However, as noted above, these new agglomerates could have distinct cohesiveness or shape, as these characteristics do not influence the values of $A_{\mathrm{r}}$. When the composite melt is resubmitted between channels 6 to 10 to the shear rate conditions imposed along the first mixing zone, $A_{\mathrm{r}}$ decreases and reaches values similar to those attained at the outlet of channel 5 .

The rate of $A_{\mathrm{r}}$ evolution along the equipment varies with GnP type, as perceived from the linear slopes indicated in Figure 6. These observations may be analyzed in light of the rupture and erosion dispersion mechanisms of agglomerated particles in melts postulated by Manas-Zloczower and 
co-workers $[40,41]$. These authors postulated that the route to dispersion depends on the magnitude of a fragmentation number, $F_{a}$, and on the on the probability for break-up, $P_{\text {break }} . F_{a}$ balances the hydrodynamic stresses against the cohesive strength of the agglomerate. As $\mathrm{F}_{\mathrm{a}}$ increases progressively above 1 , erosion $\left(2 \leq F_{a}<5\right)$ or rupture $\left(F_{a} \geq 5\right)$ will become gradually predominant. The quasi-linear progression of dispersion along the mixer seems to indicate that a single dispersion route is pursued, probably rupture, as erosion is known to be a slow process [42]. $\mathrm{P}_{\text {break }}$ is proportional to the residence time and agglomerate area. Thus, at constant stress, which is the case of the experiments performed (where the total pressure drop was kept approximately constant), the smaller the agglomerate, the longer the exposure time required to break it. As seen in Figure 6, the slopes follow the rank $\mathrm{GnPH}>\mathrm{GnPM}>\mathrm{GnPC}$, consistent with the increase in the area-to-volume ratio for these nanoparticles which, according to the particle dimensions indicated by the producer, is approximately $0.13,0.33$, and 1.0 for $\mathrm{GnPH}, \mathrm{GnPM}$, and $\mathrm{GnPC}$, respectively. Thus, Figure 6 shows that the smaller the nanoparticle (and thus, the larger its area-to-volume ratio), the slower is its kinetics of dispersion.

The discussion above remains valid for the various fGnP-PP. Nevertheless, two further observations seem relevant: (i) The overall dispersion level reached for $f \mathrm{GnP}$-PP is systematically higher compared to as-received GnP; (ii) chemical modification of the GnP surface did not significantly change the re-agglomeration behavior.

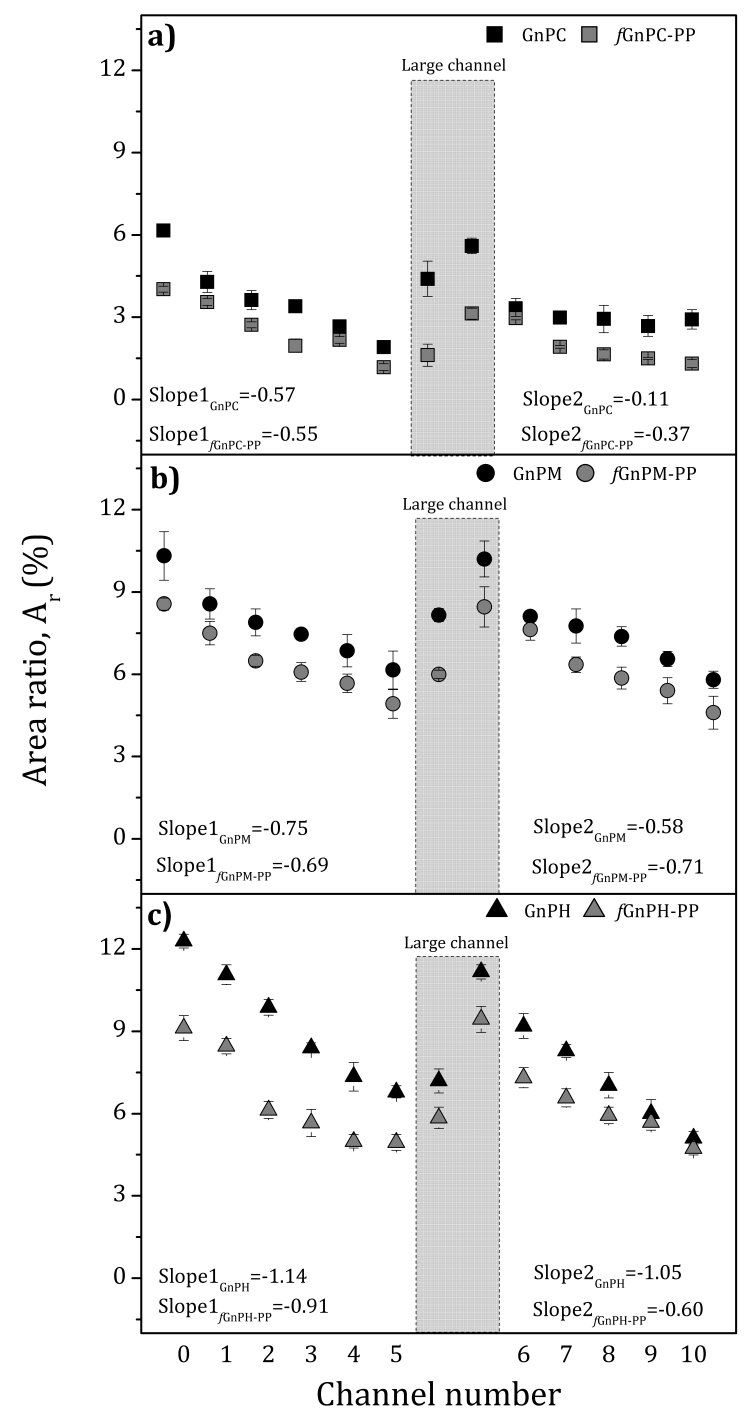

Figure 6. Evolution of dispersion (in terms of Area Ratio, $A_{\mathrm{r}}$ ) along the length of the extensional mixer of GnP and $f \mathrm{GnP}-\mathrm{PP}$ in a PP melt matrix. 


\subsection{Electrical Conductivity of the Nanocomposites}

The effects of size and surface chemistry of graphite nanoplates on the AC electrical conductivity of PP nanocomposites are shown in Figure 7a,b, respectively. PP shows a typical behavior of a dielectric material, the electrical conductivity increasing with the frequency in a logarithmic scale. The incorporation of $2 \mathrm{wt} \%$ of as-received $\mathrm{GnP}$ and fGnP-PP increased slightly the electrical conductivity of PP from $10^{-9}$ to $10^{-8} \mathrm{~S} / \mathrm{m}$ at $1 \mathrm{KHz}$. However, nanocomposites still exhibit a frequency-dependent behavior, showing that the formation of an interconnected conductive network was not achieved. As shown elsewhere [3,11,35], even at filler loadings as high as $10 \mathrm{wt} \%$, percolation may not be achieved. No significant differences on the AC conductivity of PP composites containing $2 \mathrm{wt} \%$ graphite nanoplates with different widths and thicknesses were found, however, the AC conductivity is systematically higher for the composites with larger GnP flake.

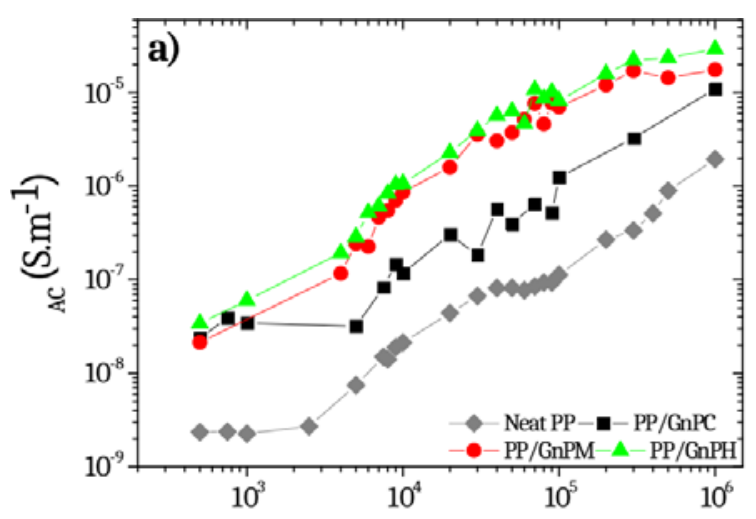

$(\mathrm{Hz})$

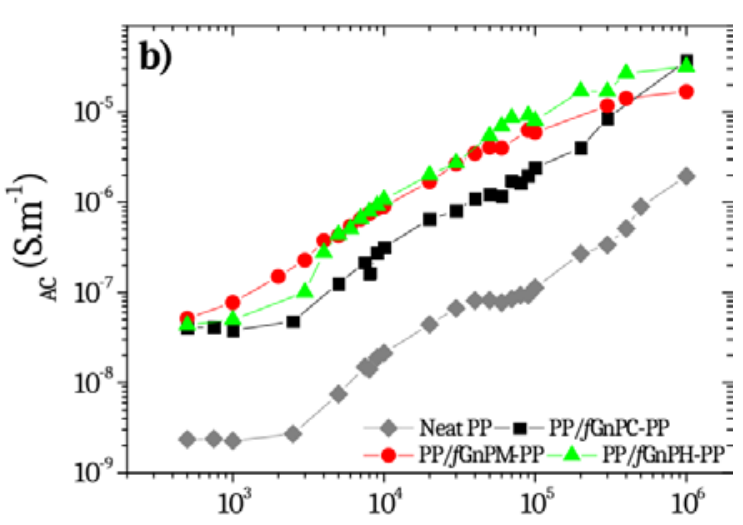

$(\mathrm{Hz})$

Figure 7. AC electrical conductivity of PP nanocomposites with 2 wt \% of (a) as-received GnP and (b) fGnP-PP.

\section{Conclusions}

The dispersion of different GnP grades in a PP melt was carried out in a prototype extensional mixer under constant hydrodynamic stress conditions, in order to investigate the influence of the GnP flake size on dispersion rate and stability. GnP flakes with larger surface area (smaller flake size) and higher bulk density presented smaller agglomerate size in the powder form and final smaller average agglomerate area, as measured by $\mathrm{OM}$ in the PP composite, in contrast with the GnP with larger flakes and lower bulk density.

The degree of dispersion, as defined by the agglomerate area ratio, $A_{r}$, increased linearly along the mixer length, irrespective of the GnP morphology and bulk density; however, the dispersion rate along the mixer was lower for the smaller flakes with higher bulk density. Once a certain dispersion level is attained, if the composite is made to flow at sufficiently low shear rates during enough time, an increase of the $A_{\mathrm{r}}$ was observed for all the GnP types, indicating re-agglomeration of $\mathrm{GnP}$, subjecting the composite to the same flow conditions as before induces dispersion, although at a slightly lower rate compared to the first mixing zone, which may be indicative of differences in the agglomerate cohesive forces before and after re-agglomeration.

Functionalization by covalent bonding polymer molecules to the $\mathrm{GnP}$ surface should increase the GnP/PP compatibility and interfacial strength; the functionalized GnP showed similar dispersion effects as observed for the pristine $\mathrm{GnP}$, however, presenting slightly higher dispersion levels.

The 2 wt \% GnP composites presented dielectric behavior, but the AC conductivity was systematically higher for the composites with larger GnP flakes (with and without functionalization). 
Acknowledgments: This work was funded by National Funds through FCT-Portuguese Foundation for Science and Technology, Reference UID/CTM/50025/2013 and FEDER funds through the COMPETE 2020 Programme under the project number POCI-01-0145-FEDER-007688. We acknowledge Mrs. Uta Reuter from Leibniz-Institut für Polymerforschung Dresden e.V. for TEM specimen preparation and image acquisition for the composites.

Author Contributions: José A. Covas designed the extensional mixer, originated the overall motivation of the work and participated in the discussion of the results. Maria C. Paiva developed the functionalization methodology, performed the statistical analysis and contributed to the discussion of the results. Raquel M. Santos performed the experimental work. Petr Formánek contributed with the TEM analysis of the composites. Sacha T. Mould performed statistical analysis of some of the data.

Conflicts of Interest: The authors declare no conflict of interest.

\section{References}

1. Geim, A.K.; Novoselov, K.S. The rise of graphene. Nat. Mater. 2007, 6, 183-191. [CrossRef] [PubMed]

2. Sur, U.K. Graphene: A rising star on the horizon of materials science. Int. J. Electrochem. 2012, 2012, 1-12. [CrossRef]

3. Santos, R.M.; Vilaverde, C.; Cunha, E.; Paiva, M.C.; Covas, J.A. Probing dispersion and re-agglomeration phenomena upon melt-mixing of polymer-functionalized graphite nanoplates. Soft Matter 2015, 12, 77-86. [CrossRef] [PubMed]

4. Tian, X.; Itkis, M.E.; Bekyarova, E.B.; Haddon, R.C. Anisotropic thermal and electrical properties of thin thermal interface layers of graphite nanoplatelet-based composites. Sci. Rep. 2013, 3, 1710. [CrossRef]

5. Randviir, E.P.; Brownson, D.A.C.; Banks, C.E. A decade of graphene research: Production, applications and outlook. Mater. Today 2014, 17, 426-432. [CrossRef]

6. Jang, B.Z.; Zhamu, A. Processing of nanographene platelets (NGPs) and NGP nanocomposites: A review. J. Mater. Sci. 2008, 43, 5092-5101. [CrossRef]

7. Bousmina, M. Study of intercalation and exfoliation processes in polymer nanocomposites. macromolecules 2006, 39, 4259-4263. [CrossRef]

8. Steurer, P.; Wissert, R.; Thomann, R.; Mülhaupt, R. Functionalized graphenes and thermoplastic nanocomposites based upon expanded graphite oxide. Macromol. Rapid Commun. 2009, 30, 316-327. [CrossRef] [PubMed]

9. Chung, D.D.L. Exfoliation of graphite. J. Mater. Sci. 1987, 22, 4190-4198. [CrossRef]

10. Bianco, A.; Cheng, H.-M.; Enoki, T.; Gogotsi, Y.; Hurt, R.H.; Koratkar, N.; Kyotani, T.; Monthioux, M.; Park, C.R.; Tascon, J.M.D.; et al. All in the graphene family-A recommended nomenclature for two-dimensional carbon materials. Carbon 2013, 65, 1-6. [CrossRef]

11. Vilaverde, C.; Santos, R.M.; Paiva, M.C.; Covas, J.A. Dispersion and re-agglomeration of graphite nanoplates in polypropylene melts under controlled flow conditions. Compos. A 2015, 78, 143-151. [CrossRef]

12. Liu, J.; Tang, J.; Gooding, J.J. Strategies for chemical modification of graphene and applications of chemically modified graphene. J. Mater. Chem. 2012, 22, 12435-12452. [CrossRef]

13. Brodie, B.C. On the Atomic Weight of Graphite. Philos. Trans. R. Soc. Lond. 1859, 149, 249-259. [CrossRef]

14. Staudenmaier, L. Verfahren zur darstellung der graphitsäure. Eur. J. Inorg. Chem. 1898, 31, 1481-1487. [CrossRef]

15. Hummers, W.S., Jr.; Offeman, R.E. Preparation of graphitic oxide. J. Am. Chem. Soc. 1958, 80, 1339. [CrossRef]

16. Stankovich, S.; Dikin, D.A.; Piner, R.D.; Kohlhaas, K.A.; Kleinhammes, A.; Jia, Y.; Wu, Y.; Nguyen, S.T.; Ruoff, R.S. Synthesis of graphene-based nanosheets via chemical reduction of exfoliated graphite oxide. Carbon 2007, 45, 1558-1565. [CrossRef]

17. Poh, H.L.; Sanek, F.L.; Sanek, F.; Ambrosi, A.; Zhao, G.; Sofer, Z.; Pumera, M. Graphenes prepared by staudenmaier, hofmann and hummers methods with consequent thermal exfoliation exhibit very different electrochemical properties. Nanoscale 2012, 4, 3515-3522. [CrossRef] [PubMed]

18. Paiva, M.C.; Simon, F.; Novais, R.M.; Ferreira, T.; Proença, M.F.; Xu, W.; Besenbacher, F. Controlled functionalization of carbon nanotubes by a solvent-free multicomponent approach. ACS Nano 2010, 4, 7379-7386. [CrossRef] [PubMed]

19. Georgakilas, V.; Kordatos, K.; Prato, M.; Guldi, D.M.; Holzinger, M.; Hirsch, A. Organic functionalization of carbon nanotubes. J. Am. Chem. Soc. 2002, 124, 760-761. [CrossRef] [PubMed] 
20. Araújo, R.; Fernandes, F.M.; Proença, M.F.; Silva, C.J.R.; Paiva, M.C. The 1,3-dipolar cycloaddition reaction in the functionalization of carbon nanofibers. J. Nanosci. Nanotechnol. 2007, 7, 3441-3445. [CrossRef] [PubMed]

21. Liebscher, M.; Gartner, T.; Tzounis, L.; Micusik, M.; Pötschke, P.; Stamm, M.; Heinrich, G.; Voit, B. Influence of the MWCNT surface functionalization on the thermoelectric properties of melt-mixed polycarbonate composites. Compos. Sci. Technol. 2014, 101, 133-138. [CrossRef]

22. Novais, R.M.; Covas, J.A.; Paiva, M.C. The effect of flow type and chemical functionalization on the dispersion of carbon nanofiber agglomerates in polypropylene. Compos. A 2012, 43, 833-841. [CrossRef]

23. Pegel, S.; Pötschke, P.; Petzold, G.; Alig, I.; Dudkin, S.M.; Lellinger, D. Dispersion, agglomeration, and network formation of multiwalled carbon nanotubes in polycarbonate melts. Polymer 2008, 49, 974-984. [CrossRef]

24. Krause, B.; Mende, M.; Pötschke, P.; Petzold, G. Dispersability and particle size distribution of CNTs in an aqueous surfactant dispersion as a function of ultrasonic treatment time. Carbon 2010, 48, 2746-2754. [CrossRef]

25. Chatterjee, S.; Nafezarefi, F.; Tai, N.H.; Schlagenhauf, L.; Nuesch, F.A.; Chu, B.T.T. Size and synergy effects of nanofiller hybrids including graphene nanoplatelets and carbon nanotubes in mechanical properties of epoxy composites. Carbon 2012, 50, 5380-5386. [CrossRef]

26. Guo, J.; Liu, Y.; Prada-Silvy, R.; Tan, Y.; Azad, S.; Krause, B.; Pötschke, P.; Grady, B.P. Aspect ratio effects of multi-walled carbon nanotubes on electrical, mechanical, and thermal properties of polycarbonate/MWCNT composites. J. Polym. Sci. B 2014, 52, 73-83. [CrossRef]

27. Morcom, M.; Atkinson, K.; Simon, G.P. The effect of carbon nanotube properties on the degree of dispersion and reinforcement of high density polyethylene. Polymer 2010, 51, 3540-3550. [CrossRef]

28. Versavaud, S.; Régnier, G.; Gouadec, G.; Vincent, M. Influence of injection molding on the electrical properties of polyamide 12 filled with multi-walled carbon nanotubes. Polymer 2014, 55, 6811-6818. [CrossRef]

29. Kim, H.; Macosko, C.W. Processing-property relationships of polycarbonate/graphene composites. Polymer 2009, 50, 3797-3809. [CrossRef]

30. Kasaliwal, G.R.; Villmow, T.; Pegel, S.; Pötschke, P. Polymer-Carbon Nanotube Composites, 1st ed.; Woodhead Publishing Series in Composites Science and Engineering; Elsevier: Cambridge, UK, 2011; pp. 92-132, ISBN 978-1-84569-761-7.

31. Kasaliwal, G.R.; Göldel, A.; Pötschke, P.; Heinrich, G. Influences of polymer matrix melt viscosity and molecular weight on MWCNT agglomerate dispersion. Polymer 2011, 52, 1027-1036. [CrossRef]

32. Socher, R.; Krause, B.; Müller, M.T.; Boldt, R.; Pötschke, P. The influence of matrix viscosity on MWCNT dispersion and electrical properties in different thermoplastic nanocomposites. Polymer 2012, 53, 495-504. [CrossRef]

33. Bai, J.B.; Allaoui, A. Effect of the length and the aggregate size of MWNTs on the improvement efficiency of the mechanical and electrical properties of nanocomposites-Experimental investigation. Compos. A 2003, 34, 689-694. [CrossRef]

34. Kalaitzidou, K.; Fukushima, H.; Askeland, P.; Drzal, L.T. The nucleating effect of exfoliated graphite nanoplatelets and their influence on the crystal structure and electrical conductivity of polypropylene nanocomposites. J. Mater. Sci. 2007, 43, 2895-2907. [CrossRef]

35. Kalaitzidou, K.; Fukushima, H.; Drzal, L.T. A new compounding method for exfoliated graphite-polypropylene nanocomposites with enhanced flexural properties and lower percolation threshold. Compos. Sci. Technol. 2007, 67, 2045-2051. [CrossRef]

36. Kalaitzidou, K.; Fukushima, H.; Drzal, L.T. Multifunctional polypropylene composites produced by incorporation of exfoliated graphite nanoplatelets. Carbon 2007, 45, 1446-1452. [CrossRef]

37. Grace, H.P. Dispersion phenomena in high viscosity immiscible fluid systems and application of static mixers as dispersion devices in such systems. Chem. Eng. Commun. 1982, 14, 225-277. [CrossRef]

38. Rodrigues, P.; Santos, R.M.; Paiva, M.C.; Covas, J.A. Development of dispersion during compounding and extrusion of Polypropylene/Graphite Nanoplates Composites. Int. Polym. Proc. 2017, 32, 614-622. [CrossRef]

39. Jamali, S.; Paiva, M.C.; Covas, J.A. Dispersion and re-agglomeration phenomena during melt mixing of polypropylene with multi-wall carbon nanotubes. Polym. Test. 2013, 32, 701-707. [CrossRef]

40. Scurati, A.; Feke, D.L.; Manas-Zloczower, I. Analysis of the kinetics of agglomerate erosion in simple shear flows. Chem. Eng. Sci. 2005, 60, 6564-6573. [CrossRef] 
41. Domingues, N.; Gaspar-Cunha, A.; Covas, J.A.; Camesasca, M.; Kaufman, M.; Manas-Zloczower, I. Modeling of agglomerate dispersion in single screw extruders. Model. Int. Polym. Process. 2010, 25, 188-198. [CrossRef]

42. Alig, I.; Pötschke, P.; Lellinger, D.; Skipa, T.; Pegel, S.; Kasaliwal, G.R.; Villmow, T. Establishment, morphology and properties of carbon nanotube networks in polymer melts. Polymer 2012, 53, 4-28. [CrossRef]

(c)

(C) 2018 by the authors. Licensee MDPI, Basel, Switzerland. This article is an open access article distributed under the terms and conditions of the Creative Commons Attribution (CC BY) license (http:/ / creativecommons.org/licenses/by/4.0/). 